\title{
O IMPACTO FINANCEIRO DAS AUDITORIAS DA QUALIDADE NAS EMPRESAS PORTUGUESAS
}

\author{
I.C.P.Batista ${ }^{1}$; G.Santos ${ }^{2 *}$ \\ 1 Instituto Politécnico do Cávado e do Ave - IPCA, Barcelos. Portugal / Escola Superior de Gestão \\ 2 Instituto Politécnico do Cávado e do Ave - IPCA, Barcelos. Portugal / Escola Superior de Tecnologia \\ *gsantos@ipca.pt
}

Artigo submetido em 23/11/2015 e aceito em 30/12/2015

\section{RESUMO}

O presente trabalho aborda como temática principal as implicações financeiras que as empresas portuguesas têm com a implementação e posterior certificação do Sistema da Qualidade e respetivas Auditorias da Qualidade. A revisão da literatura demonstra que as empresas não publicam os resultados financeiros sobre a temática em questão, tornando-se necessário adquirir informação através de um questionário. Foram enviados cerca de 126 questionários. A nossa amostra é, no entanto, de 32 questionários validados. Pode-se concluir que os 5 principais benefícios gerais, ou benefícios financeiros indiretos para as empresas portuguesas foram, respetivamente: melhoria da organização interna; melhoria da imagem da empresa; aumento da satisfação dos clientes; melhoria contínua no atendimento ao cliente; melhoria da posição competitiva. Em termos de benefícios financeiros diretos os 3 principais benefícios obtidos pelas empresas foram: Aumento do volume de negócios; Desempenho (redução de custos);Aumento da produtividade da empresa. Espera-se assim dar um contributo para o conhecimento do impacto, nomeadamente, financeiro dos Sistemas de Gestão da Qualidade e respetivas auditorias nas empresas portuguesas.

\section{THE FINANCIAL IMPACT OF QUALITY AUDITS IN PORTUGUESE COMPANIES}

\begin{abstract}
This paper discusses the main theme the financial implications that Portuguese companies with the implementation and subsequent certification of the Quality System and respective Quality Audits. The literature review shows that companies do not publish financial results on the subject in question, making it necessary to acquire information through a questionnaire. About 126 questionnaires were sent. Our sample is however 32 validados.Pode to complete questionnaires that the top 5 overall benefits or indirect financial benefits for Portuguese companies were, respectively: improving internal organization; improving the
\end{abstract}

company's image; increasing customer satisfaction; continuous improvement in customer service; improving competitive position. In terms of direct financial benefits the 3 main benefits obtained by the companies were: turnover increase; Performance (cost reduction); Increased business productivity. So it is expected to contribute to the knowledge of the impact, notably financial of Quality Management Systems and respective audits in Portuguese companies.

KEYWORDS: Quality audits; Financial impact; Continuous improvement; ISO 9001. 


\section{INTRODUÇÃO}

O termo auditoria e o termo qualidade têm o seu surgimento nas civilizações antigas. As auditorias, segundo Ben (2006), surgem com o principal objetivo de controlar o património e o minimizar conflitos entre comerciantes. Por seu turno a qualidade surge sem uma definição clara (Vasconcelhos et al.,2012).

$\mathrm{Na}$ era da Revolução Industrial a qualidade foi marginalizada e colocada de lado uma vez que apenas se queria produzir, produzir e produzir (Reilly,1994; Ben, 2006). Contudo a auditoria ganhou enfâse ao erguer-se como uma "ramificação da contabilidade" (Souza et al.,2010).

A oferta de produtos e serviços que antes eram escassos e um privilégio de alguns, passaram a ser uma necessidade do dia-a-dia. $O$ cliente com a evolução dos tempos passou a ser mais exigente. Esta evolução de mentalidades e o surgimento de individualidades ligadas à qualidade, tais como Shewhart (Ciclo PDCA), Juran (Trilogia de Juran) e Deming (14Passos de Deming para a melhoria da Qualidade) fizeram renascer a importância da qualidade. Assim, segundo Carvalho (2003) "a inspeção foi o primeiro passo na integração da qualidade como uma atividade rotineira dentro das organizações".

Este novo mundo globalizado com os mercados interligados obrigou as organizações a investirem na melhoria contínua e a darem garantias sobre os produtos e serviços que forneciam.

Assim em 1947 em Genebra, Suíça, nasce a International Organization for Standardization (ISO) que é uma federação sem fins lucrativos criada com vista à homogeneização de normas tendo como finalidade a eliminação das barreiras de harmonia global do comércio mundial.

Em 1987 a ISO publica a série de normas ISO 9000 que são uma referência para a certificação de Sistemas de Gestão da Qualidade, aceites mundialmente. Esta série é uma âncora para as organizações uma vez que baseiam-se na premissa de que através das práticas de gestão normalizadas, o Sistema da Qualidade irá fornecer confiança na saída dos produtos e satisfazer as expectativas dos clientes (CT 80 - IPQ, 2008).

Segundo Tricker (2010) um Sistema de Gestão da Qualidade eficaz deveria ser concebido para satisfazer as condições, requisitos e expectativas do comprador. Contudo serve para proteger os melhores interesses do fabricante. Uma vez que o "o ambiente competitivo em que as empresas se encontram inseridas" fez com que se torne "vital para a sua sobrevivência buscar a qualidade como caminho, talvez único, para a sua manutenção no mercado a longo prazo" (Wernke, 2000). Dentro deste contexto os princípios de Gestão da Qualidade e as práticas de gestão a eles associadas, são imprescindíveis para cobrir as necessidades e assegurar a competitividade da economia (Costa, 2008; Santos et al.,2012).

Contudo, esta busca pela sobrevivência implementando um Sistema da Qualidade acarreta investimentos que são denominados de Custos da Qualidade que segundo vários autores, Feigenbaum (1994) e Wernke (2000) de entre outros, são todos os "custos associados à definição, criação e controlo da qualidade, assim como avaliação e realimentação de conformidade com exigências em qualidade, confiabilidade, segurança e também custos associados às consequências provenientes de falha em atendimento a essas exigências, tanto no interior da fábrica como nas mãos dos clientes".

As empresas procuram constantemente o lucro e aperceberam-se rapidamente que a qualidade aliada a uma boa gestão lhes confere retornos financeiros. Sendo assim, o conceito de Auditoria foi evoluindo e deixou de ser apenas um processo para averiguar as contas das empresas, sendo adotada em diversos departamentos e aliado à qualidade passou a ser um "processo sistemático, independente e documentado para obter evidências..." com vista a "avaliar a 
adequação e implementação das políticas da organização, dos procedimentos, instruções de trabalho, bem como a eficácia dos processos em alcançar os objetivos" (Oliveira, 2010).

A constante procura por uma melhor qualidade e melhor rentabilização dos produtos e serviços levou a que uma nova geração de gestores redescobrissem as teorias de Shewhart e apelidaram, a nova forma de atingir a qualidade, de seis sigma (Carvalho, 2003).

Para Pande et al. (2000) e Trad et al. (2009) seis sigma define-se como " um sistema amplo e flexível para alcance, sustentação e maximização do sucesso do negócio", uma vez que é "unicamente orientado pelo bom entendimento dos requisitos dos clientes, pelo uso disciplinado de factos, dados e análises estatísticas, e pela atenção diligente à gestão, melhoria e reinvenção dos processos de negócios". Ou seja, o seu modelo de melhoria dos processos tem um ciclo de cinco fases DMAIC - Definir; Medir, Analisar, Melhorar e Controlar (Pande et al., 2000; Yang, 2010).

Contudo uma empresa para se manter na competição dos mercados mundiais precisa de ter visibilidade e para tal aliada à implementação do Sistema da Qualidade foram criados concursos para obtenção de Prémios de Excelência. Na Europa foi criado o Prémio de Excelência da EFQM (EEA) e em Portugal foi desenvolvido o Prémio de Excelência - Sistema Português da Qualidade (PEX-SPQ). Estes prémios visam "reconhecer as organizações líderes europeias que apresentam um percurso inquestionável de sucesso em transformar as suas estratégias em ação e melhorarem continuadamente o seu desempenho" (IPQ, 2015).

Segundo Tricker (2010) "com um Sistema de Gestão da Qualidade eficaz, o fornecedor poderá alcançar maior rentabilidade e participação no mercado e o comprador pode esperar redução nos custos, melhoria na aptidão do produto, bem como, o aumento da satisfação e, acima de tudo, o crescimento da confiança". Com este trabalho de investigação, pretende-se efetuar um estudo relativamente ao tipo de impacto financeiro que as Auditorias da Qualidade têm nas empresas portuguesas, tendo como principal objetivo: Identificar quais os fatores financeiros que influenciaram a implementação dos Sistemas da Qualidade que culminam com as Auditorias da Qualidade; Avaliar o grau de satisfação / retorno financeiro das empresas com a implementação dos Sistemas da Qualidade e respetivas Auditorias; Analisar a relação entre os custos, ganhos obtidos e a evolução da empresa no mercado.

\section{MATERIAIS E MÉTODOS}

A metodologia utilizada consistiu na análise de conteúdos literários e análise de questionários previamente enviados a empresas portuguesas que procederam e procedem à realização de Auditorias da Qualidade. A seleção das empresas foi realizada mediante os seguintes critérios: Possuir negócios em Portugal; Estarem certificadas pela NP EN ISO 9001:2008 (Qualidade) há pelo menos um ano; O questionário desenvolvido para o estudo centrou-se em três principais grupos de questões.

Num primeiro grupo de questões o objetivo era saber qual a produção da empresa, o seu tipo (micro, pequena, média ou grande empresa) e onde se situava a sua sede laboral. Tais questões foram formuladas com vista a se poder conhecer um pouco mais as empresas que respondessem aos questionários.

O segundo grupo de questões do questionário centrou-se essencialmente no Sistema da Qualidade e respetivas Auditorias da Qualidade, tentando-se averiguar em que ano foi implementado e Certificado o Sistema da Qualidade na empresa, se as Auditorias da Qualidade trouxeram custos e se esses custos maximizaram os lucros, bem como os benefícios financeiros e as dificuldades que obtiveram com a implementação do Sistema da Qualidade. Tentou-se averiguar se 
os impactos financeiros das Auditorias da Qualidade eram contabilizados, dentro de que montantes obtiveram benefícios financeiros com a implementação do Sistema da Qualidade e se as empresas portuguesas consideram ter alcançado o que ambicionavam com a Certificação da Qualidade.

As últimas cinco questões, do questionário, centravam-se em conhecer como a melhoria contínua é feita dentro das empresas, se os inquiridos pretendem atingir novas metas da qualidade, como são controlados os defeitos do produto/serviço, se pretendem concorrer a prémios de excelência com vista a melhorar a sua imagem nos mercados em que estão inseridos.

Cerca de 126 questionários foram enviados via web para endereços eletronicos das empresas que possuíam a certificação do Sistema da Qualidade. Posteriormente foram validados e considerados para o estudo da temática em causa 32 questionários obtidos através da plataforma designada de Formulários Google. Os dados obtidos foram tratados na referida plataforma e no Microsoft Office Excel 2007.

\section{RESULTADOS E DISCUSSÃO}

Sobre o primeiro grupo de questões cujo objetivo era saber informação genérica da empresa, verifica-se que se obteve um vasto leque de setores de atividade de empresas inquiridas (Figura 1).

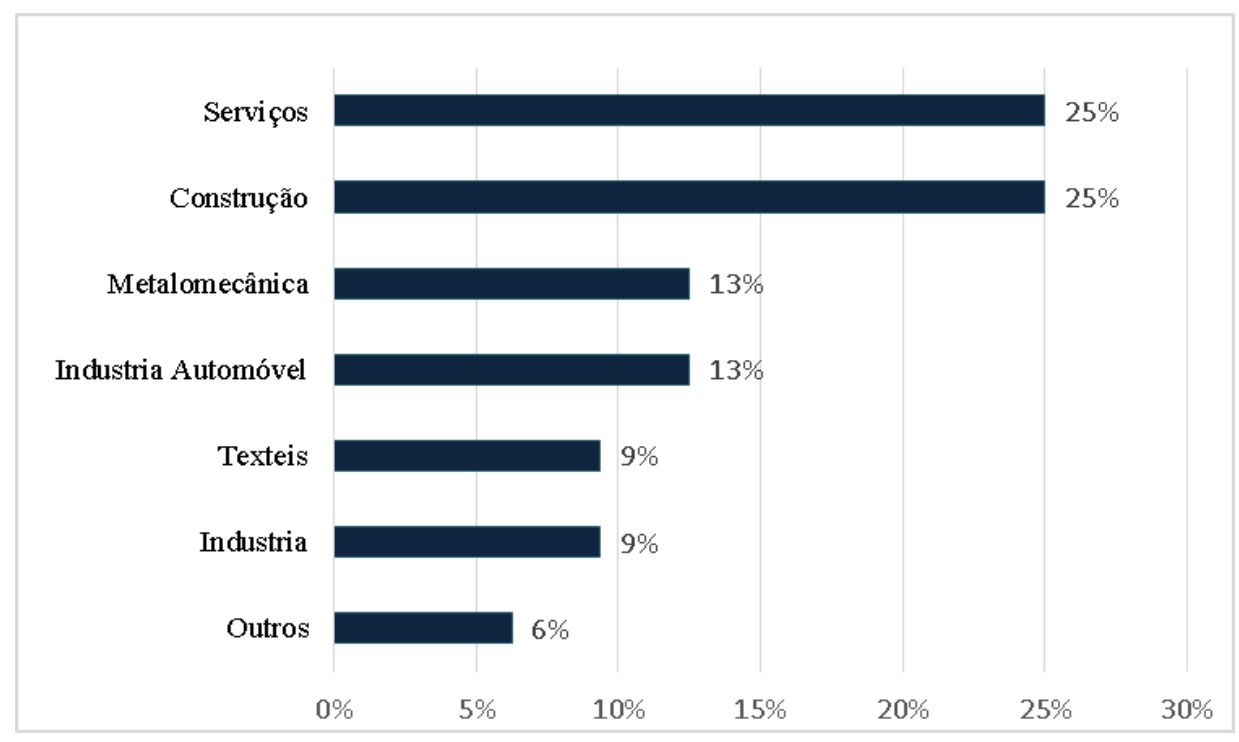

Figura 1 - Empresas agrupadas por sector de atividade (Batista, 2015).

Quanto ao tipo/tamanho de empresa, verifica-se que a maioria que respondeu ao inquérito é considerada média empresa (50\%), seguida das pequenas empresas $(28,1 \%)$, microempresas $(12,5 \%)$ e por último as grandes empresas $(9,4 \%)$ (Figura 2$)$.

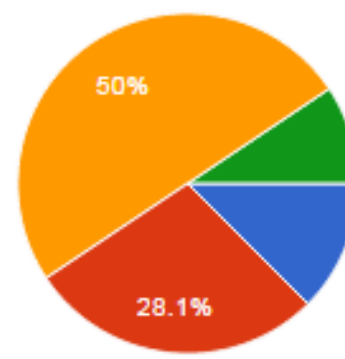

$\begin{array}{rrr}\text { Mic roempresa - até } 9 \text { funcionários } & 4 & 12.5 \% \\ \text { Pequena empresa - } 10 \text { a } 49 \text { funcionários } & 9 & 28.1 \% \\ \text { Média empresa - } 50 \text { a } 249 \text { funcionários } & 16 & 50 \% \\ \text { Grande empresa - =/> } 250 \text { funcionários } & 3 & 9.4 \%\end{array}$

Figura 2 - Tipo/tamanho de empresa (Batista, 2015). 
O estudo centra-se nas empresas com sede em Portugal, portanto a questão referente a tal informação era deveras importante e verificou-se que a totalidade dos questionários respondidos possui sede em território português (Figura 3).

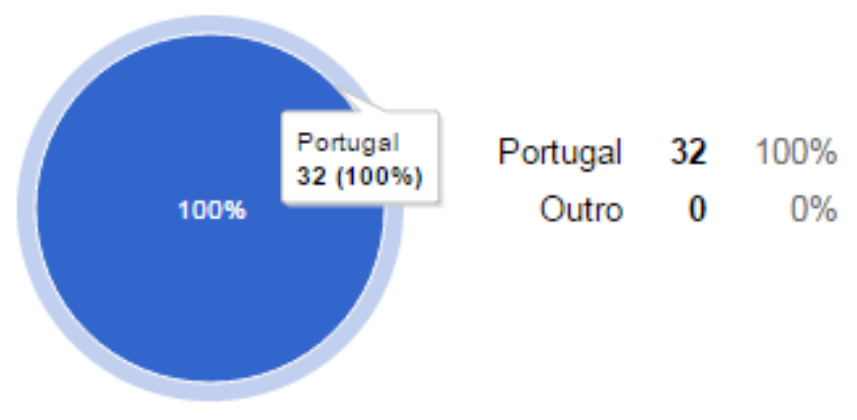

Figura 3 - Sede das empresas inquiridas (Batista, 2015).

O segundo grupo de questões do questionário tentava averiguar questões centradas essencialmente no Sistema da Qualidade, respetivas Auditorias da Qualidade, bem como, averiguar os impactos financeiros das Auditorias da Qualidade. Assim, analisando o ano em que as empresas investiram para possuir um Sistema da Qualidade certificado verifica-se que as datas variam, essencialmente, entre 1989 e 2013.

Relativamente ao apuramento para saber se as Auditorias da Qualidade tinham trazido mais custos às empresas portuguesas, verificou-se que 65,6\% das empresas consideraram que sim, que realmente houve mais custos e apenas $34,4 \%$ consideram que não houve qualquer custo acrescido (Figura 4).

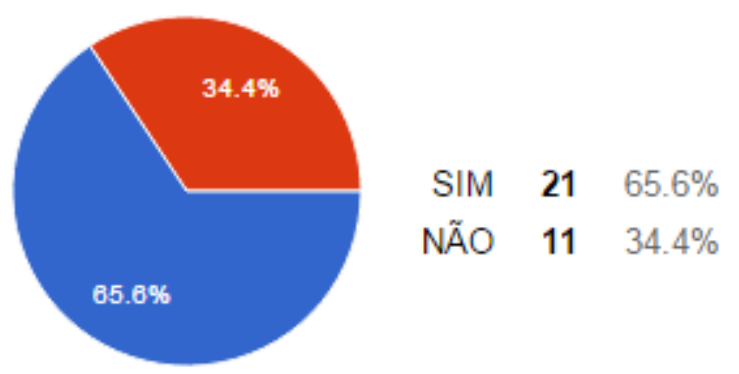

Figura 4 - Custos com as AQ (Batista, 2015).

Aos inquiridos foi questionado se consideravam que os custos relativamente às auditorias da qualidade tinham maximizado os lucros, tendo-se verificado que $81,3 \%$ consideraram que sim, havendo apenas seis empresas a julgarem que esses custos não maximizaram os lucros (Figura 5). 


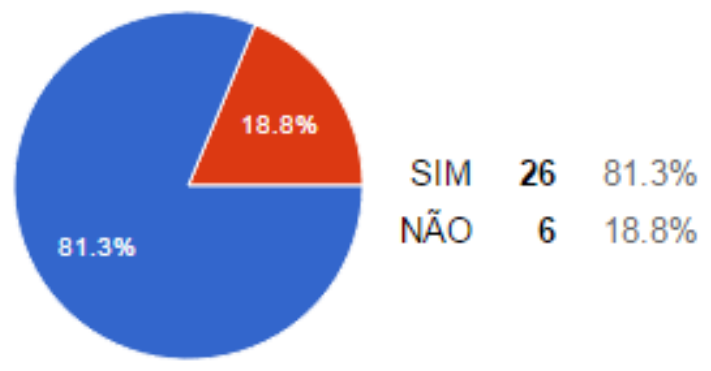

Figura 5 - Custos maximizaram os lucros (Batista, 2015).

Analisando conjuntamente a Figura 4 e a Figura 5 podemos auferir que apesar da existência de uma grande percentagem de empresas a considerar ter havido uma sobrecarga dos custos com as Auditorias da Qualidade, as mesmas concordam que esses custos acabaram por maximizar os lucros da organização.

Conclui-se que 50\% das empresas consideram terem tido mais custos com as Auditorias da Qualidade mas que mesmo assim esses custos maximizaram os lucros, tornando-se vantajoso para a organização a execução de tais auditorias.

A questão para averiguar quais os principais benefícios gerais que o Sistema de Gestão da Qualidade e respetivas Auditorias da Qualidade tinham trazido para a empresa, reverteram nos resultados das Figuras 6 e 7.

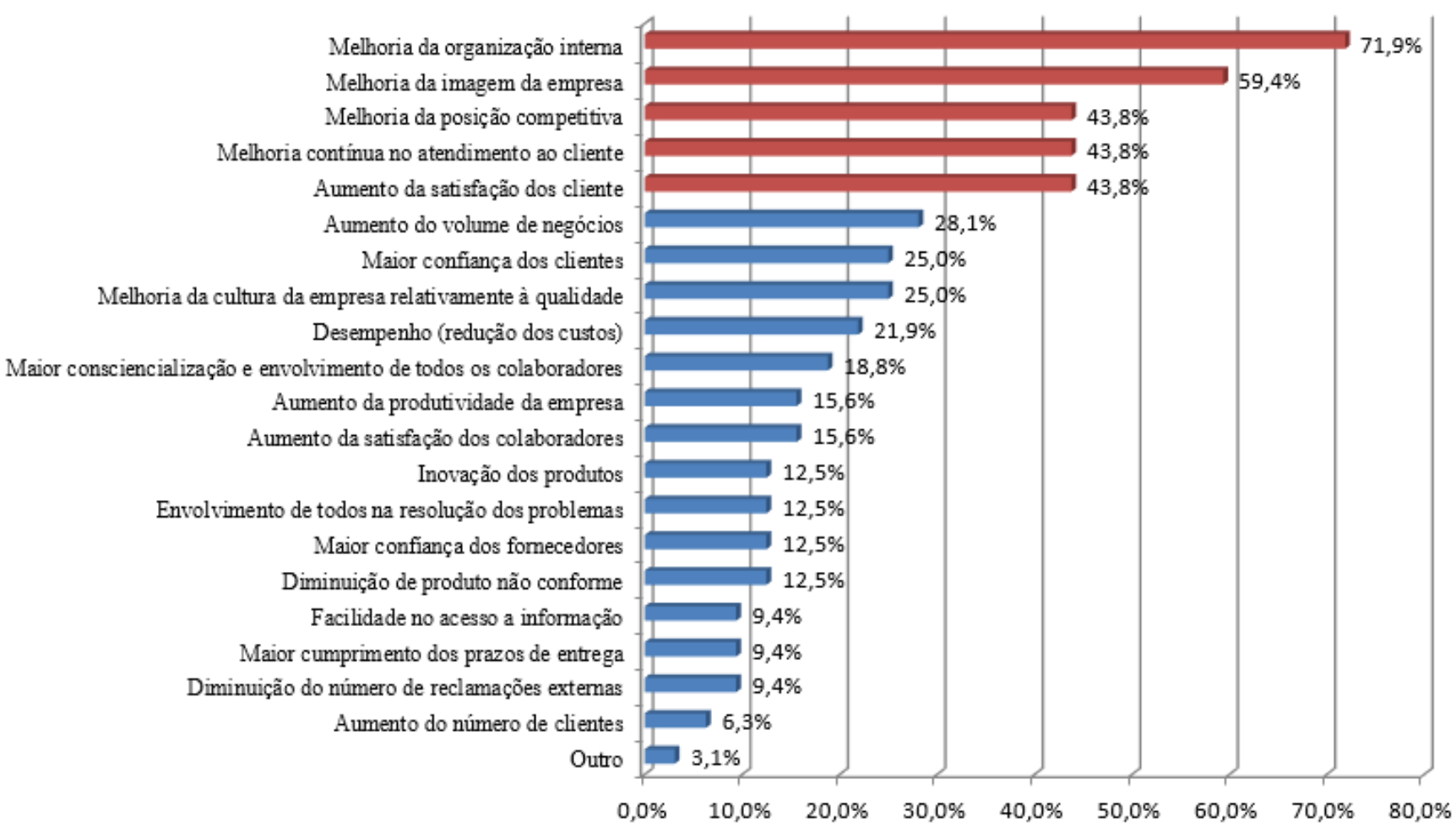

Figura 6 - Principais benefícios gerais da certificação do Sistema da Qualidade (Batista, 2015). 


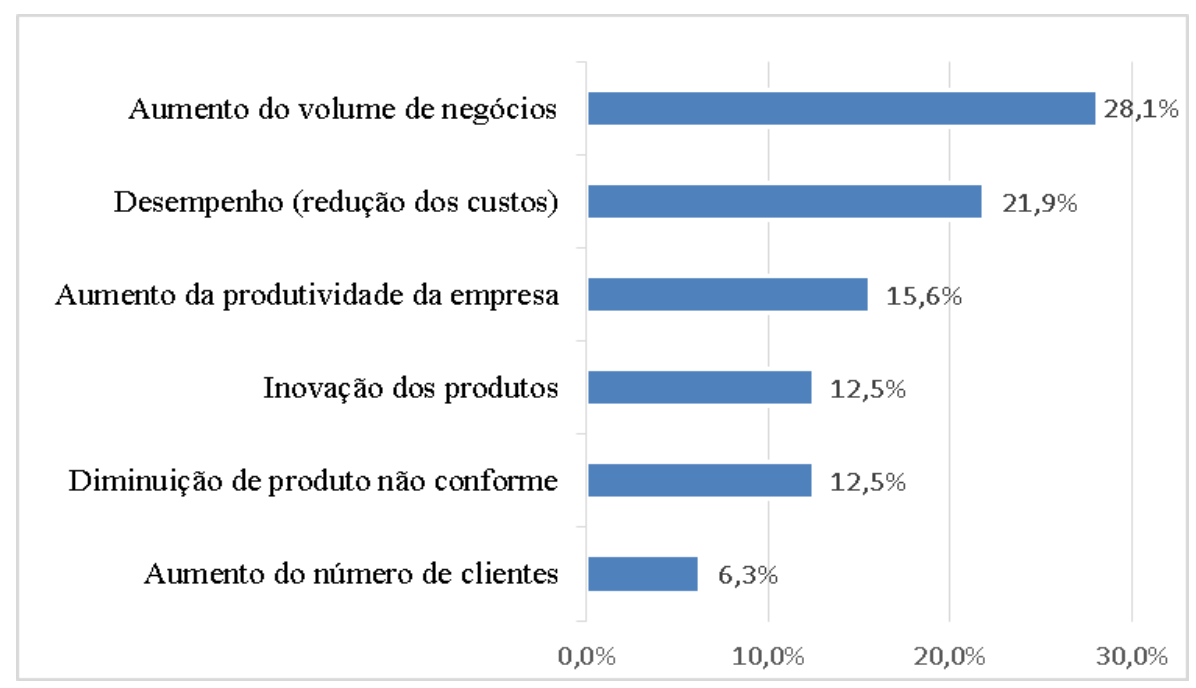

Figura 7 - Principais benefícios financeiros (Batista, 2015).

Pode-se concluir que os 5 principais benefícios gerais, ou benefícios financeiros indiretos para as empresas portuguesas foram, respetivamente: 1) melhoria da organização interna $(71,9 \%)$; 2) melhoria da imagem da empresa $(59,4 \%)$; 3) aumento da satisfação dos clientes $(43,8 \%) ; 4)$ melhoria contínua no atendimento ao cliente (43,8\%); e 5) melhoria da posição competitiva $(43,8 \%)$.

Em termos de benefícios financeiros directos os 3 principais benefícios obtidos pelas empresas foram: 1) Aumento do volume de negócios $(28,1 \%)$; 2) Desempenho (redução de custos) $(21,9 \%) ; 3)$ Aumento da produtividade da empresa $(15,6 \%)$.

Tais resultados demonstram que embora os custos da qualidade sejam investimentos avultados e muito difíceis de suportar por algumas empresas, o seu retorno acaba por advir em ganhos na produtividade e lucratividade pois a melhoria da empresa acaba por rentabilizar o trabalho não havendo perdas na produção de um produto nem custos associados à má qualidade de um produto ou serviço. Isso dá origem através de marketing a uma melhor imagem da empresa criando credibilidade e satisfação dos clientes fomentando uma presença no mercado em que está inserido, o que acaba por se traduzir numa melhoria da sua posição competitiva. Estes retornos financeiros indirectos acabam por se traduzir em retornos financeiros diretos como o aumento de um volume de negócios originando a necessidade de maior produtividade da empresa mas com redução nos custos nas fases de desenvolvimento e finalização de um produto/serviço.

Relativamente à questão para averiguar quais as principais dificuldades que o Sistema da Qualidade e respetivas Auditorias da Qualidade tinham trazido para a empresa, obteve-se os resultados explicitados na Figura 8. 


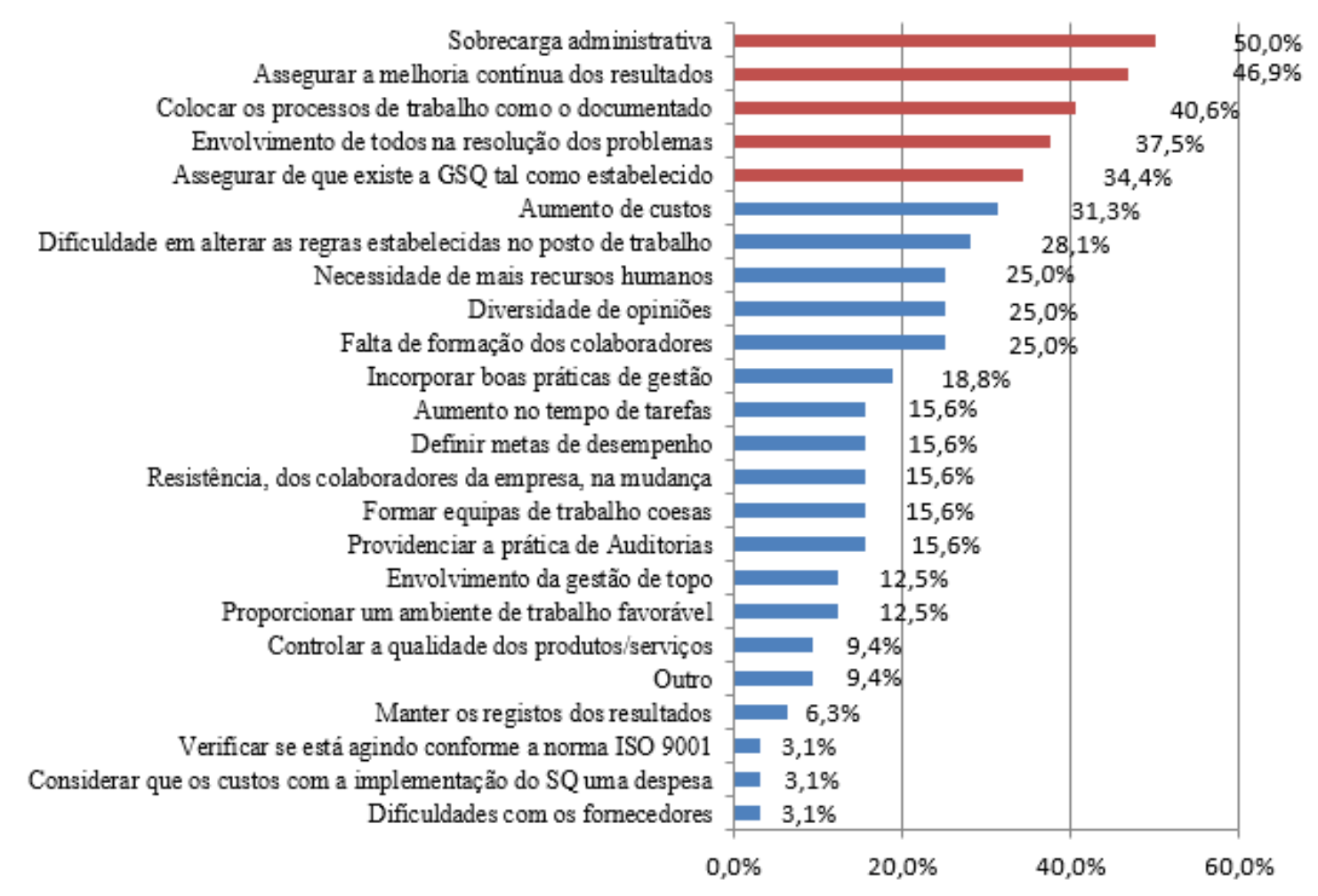

Figura 8 - Principais dificuldades na implementação e posterior certificação do SQ (Batista, 2015).

A partir da análise da Figura 8 conclui-se que as cinco principais dificuldades que os inquiridos encontraram com a implementação do Sistema de Gestão da Qualidade, ou decorrentes da certificação do Sistema de Gestão da Qualidade foram: 1) Sobrecarga administrativa (50\%); 2) Assegurar a melhoria contínua dos resultados (46,9\%); 3) Colocar os processos de trabalho como o documentado (40,6\%); 4) Envolvimento de todos na resolução dos problemas (37,5\%); e/ou 5) Assegurar de que existe a Gestão do Sistema da Qualidade tal como estabelecido (34,4\%).

Tais dificuldades incorrem porque as empresas não se encontram preparadas para as mudanças. O termo qualidade e toda a temática envolvente é um trabalho recente que se encontra em constante aperfeiçoamento uma vez que gestores ainda redescobrem novas formas de aperfeiçoar os processos organizacionais por forma a atingir desempenhos quase perfeitos de redução de custos e melhoria da qualidade. Sendo assim, a constante necessidade de informação leva a uma sobrecarga administrativa e um acumular de funções.

A teoria, contudo, pode ser exemplar mas aquando da sua aplicação prática pode tornar-se demasiado generalista, dificultando a forma de colocar em prática os processos de acordo com a teoria.

Em muitas empresas, as chefias na maioria das vezes tomam decisões sem ouvir a opinião dos seus colaboradores e sem informar quais os objetivos da organização. Assim os processos não fluem e a forma de gerir recursos humanos não é a melhor. Visto que o objectivo é tentar orientar as mentalidades para um único fim dentro da organização, se os colaboradores não o conhecerem, não farão parte dele, o que dificulta alcançar a meta dos objetivos propostos.

Relativamente às Auditorias da Qualidade foi colocada a questão se os impactos financeiros de tais auditorias eram contabilizados. 
Dos dados obtidos, apresentados na figura 9, retira-se a informação que nas auditorias internas, em termos de contabilização, nem todas as empresas o fazem, havendo uma percentagem próxima entre o $\operatorname{sim}(53,1 \%)$ e o não $(46,9 \%)$. Por outras palavras, as percentagens não são iguais apenas por 2 empresas que consideram que realmente conseguem contabilizar.

\section{AUDITORIA INTERNA}

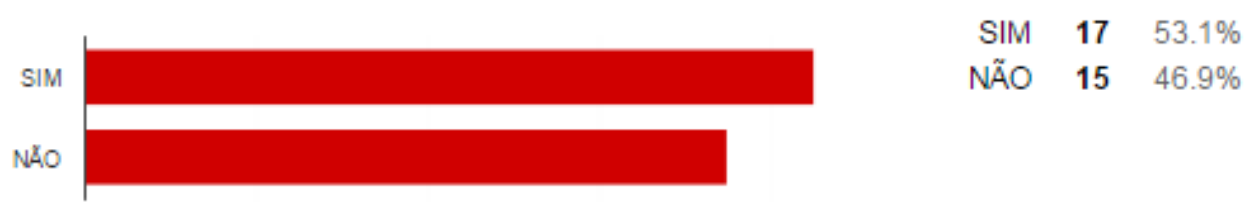

\section{AUDITORIA EXTERNA}
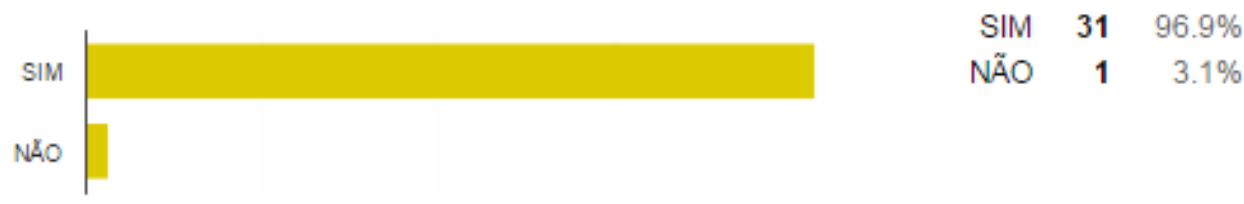

Figura 9 - Contabilização dos impactos financeiros dentro das organizações relativamente às AQ

Relativamente às auditorias externas, os dados já são mais antagónicos havendo 96,9\% a dizer que sim, realmente os dados são contabilizados, e apenas $3,1 \%$ a dizer que não contabiliza. Ou seja, somente uma única empresa é que ainda não tem incutido dentro da sua gestão a contabilização dos gastos com as auditorias externas.

A contabilização das auditorias externas deve-se ao facto de serem auditorias praticadas por uma entidade externa à organização que estabelece um preço fixo. As auditorias internas já não são contabilizadas porque são auditorias realizadas por colaboradores da empresa que acumulam funções não havendo necessidade de averiguar os custos que elas englobam.

Questionados sobre que montantes consideravam ter tido benefícios financeiros com a implementação do Sistema de Gestão da Qualidade e respetivas Auditorias da Qualidade, de uma forma global, verificou-se que os inquiridos responderam todos e que as organizações obtiveram a maior parte dos lucros situados entre $10000 €$ a $100000 €$ cujos resultados são apresentam-se na Figura 10:

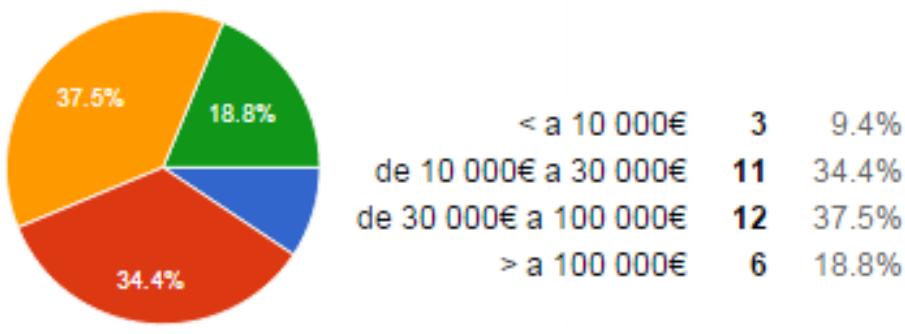

Figura 10 - Benefícios Financeiros com as Auditorias da Qualidade

É possível verificar que 12 empresas obtiveram lucros entre os $30000 €$ e os $100000 €$ (37,5\%), seguida por 11 empresas que afirmam ter tido benefícios financeiros correspondidos entre 
os 10000 e $30000 €(34,4 \%)$. Já 3 empresas obtiveram benefícios abaixo dos $10000 €$ e 6 inquiridos afirmam ter tido benefícios acima dos $100000 €$.

Analisando o tipo de empresa com os montantes dos benefícios financeiros verificou-se que das três grandes empresas inquiridas apenas duas consideram ter tido benefícios superiores a 100 $000 €$ e que das dezasseis médias empresas, quatro informam que também obtiveram ganhos acima dos $100000 €$.

Relativamente aos benefícios inferiores a $10000 €$ pode-se verificar que uma empresa é micro, uma é pequena e outra é considerada de grande empresa. Também, se verificou que das microempresas que responderam ao questionário uma obteve lucros entre os $10000 €$ e os $30000 € \mathrm{e}$ duas conseguiram atingir benefícios compreendidos entre os $30000 €$ e os $100000 €$.

Inquiriu-se sobre se tinham atingido o que ambicionavam com a certificação da qualidade. Os resultados são apresentados na Figura 11.

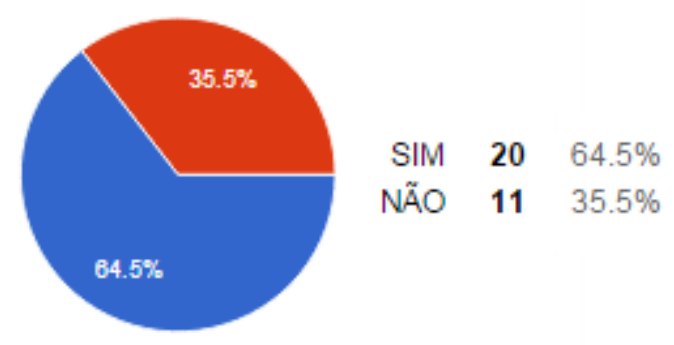

Figura 11 - A empresa alcançou tudo que ambicionava com a Certificação da Qualidade?

Em síntese, das 32 empresas que responderam aos questionários é possível constatar que uma empresa não respondeu à questão acima descrita e que das 31 que responderam 20 consideram que alcançaram muito do que necessitavam com a Certificação da Qualidade. Contudo 11 inquiridos afirmam que ainda não alcançaram tudo e pretendem mais. De uma forma geral, as empresas que afirmam ainda não ter atingido tudo que ambicionavam com a Certificação da Qualidade retorquem que a melhoria é um processo continuo e para tal não é apenas por ter a Certificação do Sistema de Gestão da Qualidade que conseguiram chegar à melhoria.

Sobre as últimas cinco questões, do questionário, pretendia-se saber de que forma a melhoria contínua é feita dentro das empresas, se pretendiam atingir novas metas de qualidade, como eram controlados os defeitos do produto/serviço, e se planeavam concorrer a prémios de excelência com vista a melhorar a sua imagem nos mercados onde estão inseridos. Uma análise detalhada da Figura 12 permite verificar que os inquiridos afirmam que as cinco principais formas de melhoria contínua dentro da organização são:

1) Implementando correcções de forma a retificar situações não conformes $(59,4 \%)$;

2) Analisando as situações de não conformidade (N/C) e implementando ações corretivas (AC) de forma a evitar a sua repetição $(56,3 \%)$;

3) Pesquisando e compreendendo as necessidades e as expectativas dos clientes (46,9\%);

4) Fomentando a confiança e eliminando o medo e a insegurança $(43,8 \%)$; e/ou

5) Formando os colaboradores sobre métodos e ferramentas da melhoria contínua (MC) $(37,5 \%)$. 


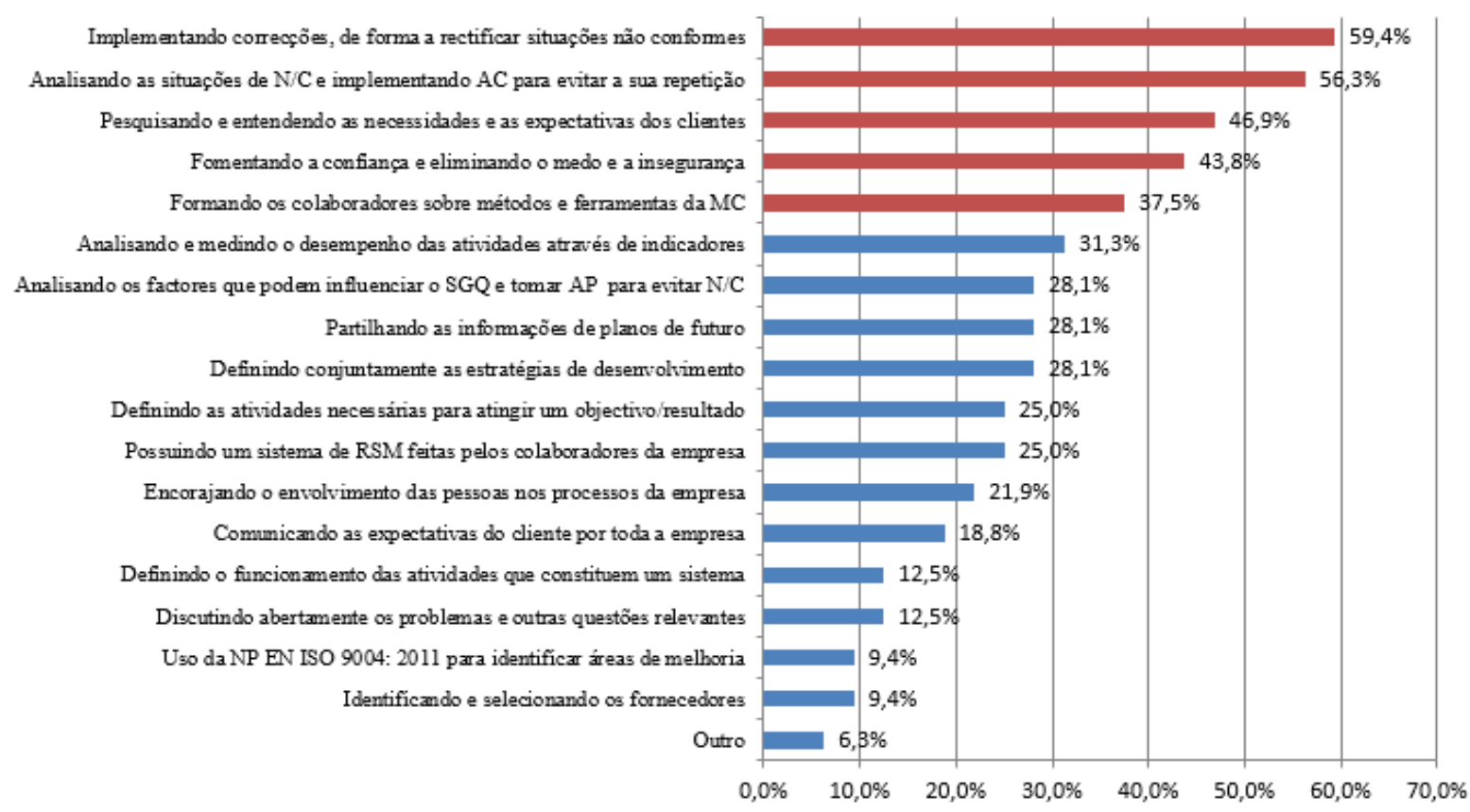

Figura 12 - Melhoria contínua praticada dentro das organizações inquiridas (Batista, 2015).

Colocada a questão se os inquiridos pretendiam atingir a qualidade seis sigma, verificou-se que $78,1 \%$ afirmam que não pretendem atingir tal qualidade (Figura 13). Possivelmente porque não dispõem de uma organização capaz de potenciar tal sistema, que sabemos ser excelente, mas simultaneamente muito exigente.

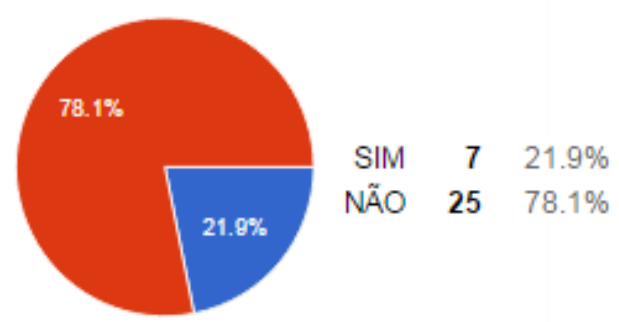

Figura 13 - Adesão à qualidade Seis Sigma das organizações inquiridas (Batista, 2015).

Com vista a uma constante melhoria contínua foi questionado se futuramente pretendiam concorrer ao PEX-SPQ ou ao Prémio de Excelência da EFQM. (Figura 14).

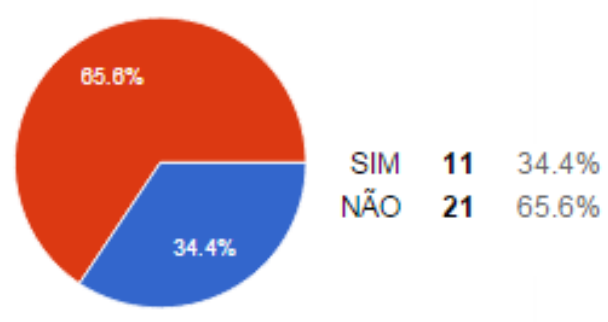

Figura 14 - Resposta à questão se pretendiam concorrer ao PEX-SPQ ou ao Prémio de Excelência da EFQM (Batista, 2015).

Analisando detalhadamente, aufere-se que 65,6\% dos inquiridos não pretende concorrer aos prémios e que apenas 11 empresas almejam o reconhecimento público que o prémio possa trazer. 


\section{CONCLUSÃO}

Apesar de haver limitações no âmbito da obtenção de informação de estatísticas referentes à temática em estudo, os resultados do inquérito indicam que este tipo de investigação pode ser um método válido para obter informação aprofundada dos impactos financeiros das Auditorias da Qualidade.

Na continuação do trabalho da presente temática propõem-se as seguintes extensões:

Expandir para novos estudos de novas temáticas: A qualidade seis sigma ainda está pouco difundida nas organizações portuguesas e pode suscitar novas questões como por exemplo: Porque é que as empresas portuguesas têm muitas dificuldades em atingir a qualidade seis sigma? Quais os impactos financeiros que a qualidade seis sigma tem nas organizações?

Estudos futuros sobre a mesma temática mas com um universo de inquiridos mais extenso por forma a comparar se as conclusões são as mesmas.

\section{REFERENCIAS}

BATISTA, I.C.P. O Impacto Financeiro das Auditorias da Qualidade. Dissertação de Mestrado. Escola Superior de Gestão - Instituto Politécnico do Cávado e do Ave - Barcelos, Portugal. 2015.

BEN, A. The modern quality movement: Origins, development and trends. Total Quality Management \& Business Excellence. Volume 17, Issue 2, p. 179-203, 2006.

CARVALHO, D. História da Engenharia e Gestão Industrial. Universidade do Minho, 2003.

CT 80 (APQ). NP EN ISO 9001 - Sistemas de gestão da Qualidade Requisitos. $3^{\circ}$ edição, 2008.

COSTA, J. Sistemas de Gestión de la Calidad en las Empresas Portuguesas: Implantación, Impacto y Rendimiento. Doctoral Thesis, University of Seville, Spain. 2008.

FEIGENBAUM, A.V. Controle da Qualidade Total, Tradução: Regina Cláudia Loverri; Revisão técnica: José Carlos de Castro Waeny. São Paulo: Makron Books, 1994. 205 p. 1994.

IPQ (Instituto Português da Qualidade). Consultado a 22 de Julho de 2015. Acedido em http://www1.ipq.pt/

ISO (International Organization for Standardization). Consultado a 10 de Outubro de 2014. Acedido em http://www.iso.org/

PANDE, P. S.; NEUMAN, R. P.; CAVANAGH, R. The six sigma way: how GE, Motorola and other top companies are honing their performance. New York: McGraw-Hill, 2000.

OLIVEIRA, R. Guia Interpretativo NP EN ISO 9001:2008. APCER - A Marca de Certificação. 2010.

PANDE, P.S., NEUMAN, R.P. and CAVANACH, R.R. The Six Sigma Way. McGraw-Hill, New York. 2000.

REILLY, N. B. Quality: What Makes It Happen?. (New York: Van Nostrand Reinhold). 1994.

SANTOS, G.; COSTA, B.; LEAL, A. The estimation of the return on firms'investments - as to ISO 9001. International Journal of Engineering, Science and Technology, v.4, n.2, p.46-57, 2012.

SOUZA, L.A.A.; DYNIEWICZ, A.M.; KALINOWSKI, L.C. Auditoria: uma abordagem histórica e atual. Nursing (São Paulo); v.14, n.165, p.108-114, 2012.

TRAD, S.; MAXIMIANO, A. Seis Sigma: Factores Críticos de Sucesso para a sua Implementação. RAC, Curitiba, v.13, nº 7 , p.647-662, Outubro, 2009.

TRICKER, R. ISO 9001: 2008 for Small Businesses. $4^{\circ}$ edição. 2010.

VASCONCELlOS, A.; LUCAS, S. Gestão pela Qualidade dos Primórdios aos Modelos de Excelência em Gestão. Congresso Nacional de Excelência em Gestão. Anais... 2012. 
WERNKE, R. (2000). Custos da Qualidade: uma abordagem prática. Conselho Regional de Contabilidade do Rio Grande do Sul- CRC/RS, 2000.

YANG, Ching-Chow. Six Sigma, Quality Management and Six Sigma. Abdurrahman Coskun (Ed.), ISBN: 978-953307-130-5, InTech, 2010. 